\title{
How to Counter the Problem of R1 Resection in Duodenopancreatectomy for Pancreatic Cancer?
}

\author{
Eliane Angst • Corina Kim-Fuchs • \\ Yojena Chittazhathu Kurian Kuruvilla • \\ Daniel Inderbitzin • Matteo Montani • \\ Daniel Candinas • Beat Gloor
}

Received: 24 August 2011 / Accepted: 11 November 2011 / Published online: 10 January 2012

(C) 2012 The Society for Surgery of the Alimentary Tract

\begin{abstract}
Objective Although duodenopancreatectomy has been standardized for many years, the pathological examination of the specimen was re-described in the last years. In methodical pathological studies up to $85 \%$ had an R1 margin. ${ }^{1,2}$ These mainly involved the posterior und medial resection margin. ${ }^{3}$ As a consequence we need to optimize and standardize the pathological workup of the specimen and to extend the surgical resection, where possible without risk for the patient.

Method and Result In an instructive video we show the technique of duodenopancreatectomy with emphasis on the dorsal and medial resection margin. Furthermore we show the standardized pathological workup of the specimen, involving the reporting of all the resection margins.

Conclusion To accurately determine R1 status at the posterior and medial resection margin, a close collaboration between pathologist and surgeon is crucial. Pathologists do a standardized workup of the resected specimen with staining of the surfaces and systematic analysis of all the resection margins. Surgeons need to extend the resection of the pancreatic head to the superior mesenteric artery by dorsal dissection.
\end{abstract}

Financial Support This work was supported by the Association for Research in Surgery of the Swiss Surgical Society, the Novartis Foundation and the Bernische Krebsliga Switzerland.

This video was presented May $26^{\text {th }} 2011$ at the Swiss Surgical Society Meeting in Geneva.

Electronic supplementary material The online version of this article (doi:10.1007/s11605-011-1791-4) contains supplementary material, which is available to authorized users.

E. Angst $(\bowtie) \cdot$ C. Kim-Fuchs $\cdot$

Y. Chittazhathu Kurian Kuruvilla • D. Inderbitzin • D. Candinas ·

B. Gloor

BHH D120, Department of Visceral Surgery and Medicine,

Inselspital,

3010, Bern, Switzerland

e-mail: eliane.angst@insel.ch

M. Montani

Institute of Pathology, University of Bern,

Bern, Switzerland
Keywords Pancreatic cancer Teaching video $\cdot$ Resection margin · Pathology

Acknowledgements We thank Gianni Pauciello for the excellent technical production and Trevor John Roling for the dubbing of the video.

\section{References}

1. Verbeke CS, Leitch D, Menon KV, McMahon MJ, Guillou PJ, Anthoney A. Redefining the R1 resection in pancreatic cancer. Br J Surg 2006;93:1232-1237.

2. Esposito I, Kleeff J, Bergmann F, Reiser C, Herpel E, Friess H, Schirmacher P, Buchler MW. Most pancreatic cancer resections are R1 resections. Ann Surg Oncol 2008;15:1651-1660.

3. Sobin LH, Gospodarowicz MK, Wittekind C. TNM Classification of Malignant Tumours. Weinheim: Wiley-VCH, 2009. 